\title{
CHARACTERISATION OF PHYSICO-CHEMICAL AND ANTIOXIDANT PROPERTIES OF OIL PALM TRUNK SAPS AS AFFECTED BY THE STORAGE TIME IN COMPARISON TO NIPA SAP
}

\author{
SYAZANA SULAIMAN*; SHIMA JAFARZADEH* and FAZILAH ARIFFIN*
}

\begin{abstract}
In this study, freshly squeezed oil palm trunk sap (OPTOsap) and sap of oil palm trunk that had been stored for 60 days (OPT60sap) were characterised and compared with a nipa sap (Nsap) as a control sample in terms of their physico-chemical and functional properties. The results indicated that when the two OPT saps were compared, trunk storage significantly impacted the latter sap's composition. As the storage period increased, the sap became darker and its sugar content increased. Further, the OPT saps showed significant amounts of antioxidant contents, with greater nutritional value compared to Nsap. The OPT0sap's viscosity was found to be the lowest, whereas the Nsap's was the highest, with values of $0.87 \pm 0.07 \mathrm{mPa}$.s and $3.77 \pm 0.09 \mathrm{mPa} . \mathrm{s}$, respectively. The OPTOsap had the lowest $\mathrm{pH}$, whereas Nsap had the highest. In conclusion, in comparison to Nsap, the OPT saps demonstrated better features in terms of antioxidant capacity and higher reducing sugar content. However, OPT saps had greater acidity and darker colour.
\end{abstract}

Keywords: OPT saps, physico-chemical properties, antioxidant properties, storage time.

Date received: 2 January 2019; Sent for revision: 26 March 2019; Accepted: 19 June 2019.

\section{INTRODUCTION}

Environmental pollution, production costs, and harmful effects on animal and human health could be reduced by using sustainable resources such as agro-based industry and agricultural waste as raw contents (Yunus et al., 2003). The Malaysian Palm Oil Board announced that in 2013, about 5.23 million hectares of land were planted with oil palm, Elaeis guineensis (Shahirah et al., 2015). Replanting of old oil palm should occur every 20 to 25 years because of a reduction in their oil productivity as well as the difficulty in collecting their fruit (Goh et al., 2011). This implies that nearly 70 million old oil palm are felled in Malaysia annually; this number of oil palm has the potential to produce nearly 15 million tonnes of oil palm trunks (Mumtaz et al., 2010). As the oil palms are felled, the sugary sap

\footnotetext{
* Food Biopolymer Research Group,

Food Technology Division,

School of Industrial Technology,

Universiti Sains Malaysia,

11800 Minden, Pulau Pinang, Malaysia.

E-mail: fazilah@usm.my
}

(85.2 $\mathrm{g} \mathrm{litre}^{-1}$ sugar) mainly glucose, and followed by fructose, sucrose, arabinose, and galactose were usually ignored. This sap was studied to increase the sugar content when the trunk was stored before squeezing (Yamada et al., 2010). Previously, several studies had been carried out to utilise this sap, such as production of ethanol and lactic acid bacteria (Kosugi et al., 2010), characterisation of the sap (Yamada et al., 2010), hydrogen production by bacteria (Noparat and Prasertsan, 2011) and carbon feedstock for bacterial growth (Lokesh et al., 2012). However, none of these researches use of the sap as an ingredient in food. The food industry could make good use of this sap to produce syrup since it contains glucose as the major sugar and significant amount of vitamins. Syrups are normally utilised as sweeteners and flavourings in the production of baked goods and confections (Phaichamnan et al., 2010). Any changes in the chemical composition of the sap impact the final product which uses the sap. Any changes in sugar content, the field and type of application for the syrup will change accordingly. Further, the initial sugar content could impact the sap's processing time into syrup. 
This study was an attempt to examine the chemical and physical features of oil palm trunk saps (OPT saps), which may have potential as a new, affordable, renewable product for use in the food industry, at two trunk's storage times. The saps from freshly felled oil palm trunk (OPT0sap) and 60 days stored oil palm trunk were chosen (OPT60sap) because the sugar content were minimum at 0 day and maximum at 60 days. The type of major sugar composition differs significantly at these two storage times as well (Yamada et al., 2010). These analyses were done concurrently with comparison with the sap of the nipa tree. Nipa sap was chosen as a control due to its high sugar content which allows it to be a source of alternative sweetener. The present study aimed to characterise the OPT saps based on two distinct storage periods ( 0 day and 60 days) and then to compare these findings with the characteristics of nipa sap as a control sample.

\section{MATERIALS AND METHODS}

\section{Chemicals and Reagents}

Sucrose, fructose and glucose from Sigma (MO, USA) and disodium ethylenediaminetetraacetate acid (Ca-EDTA) were purchased from Fluka, SigmaAldrich (Switzerland). In order to run the antioxidant analysis, ascorbic acid and Folin-Ciocalteu reagent were purchased from Merck (Darmstadt, Germany). The sodium carbonate was from R\&M Chemicals (Selangor, Malaysia) and the Trolox and DPPH were purchased from Aldrich, Sigma-Aldrich (MO, USA).

\section{Extraction of Saps}

The OPT saps by were collected mechanically pressing the oil palm trunks, according to the method described by Murata et al. (2013), using a hydraulic press for 0 days and 60 days respectively using a specially designed compression machine by Murata et al. (2013). The trunk used in this study was at 25 years of age, tenera type from Ara Kuda, Kedah, Malaysia. This study used OPT saps from two different trunk storage time. The first sap was obtained by squeezing freshly cut trunk (OPT0sap); the second sap was obtained by squeezing trunk which had been kept for 60 days at room temperature (OPT60sap). The control sample was frozen nipa sap (Nsap) purchased from a local seller in Pendang, Kedah. The saps were subjected to centrifugation at $7000 \mathrm{rpm}$ for $15 \mathrm{~min}$ to remove insoluble solids. All the collected saps were kept at $-18^{\circ} \mathrm{C}$ prior to use.

\section{Sugar Content Determination}

Using a method developed by Bazinet et al. (2007), the saps' sugar content was examined. This method utilised high performance liquid chromatography (HPLC) in conjunction with a refractive index (RI) detector (Waters 2414, USA).

\section{Colour Determination}

A Minolta Spectrophotometer CM-3500d (Osaka, Japan) was used to analyse the colour of the sap. Prior to this analysis, white and blank calibration were used for spectrophotometer calibration. A white calibration box covered a large target mask which was then integrated into the reflection settings. The prepared sap was placed into the sample cell $(10 \mathrm{~mm})$ and the final values were measured. The outcomes were displayed as $\mathrm{L}^{*}$, $\mathrm{a}^{*}$ and $\mathrm{b}^{*}$ colour space, as suggested by the Commission Internationale de I'Eclairage (CIELAB).

\section{Viscosity Measurement}

A viscometer (Vibro Viscometer SV-10, Japan) was used to measure the viscosity of the saps. Samples of approximately $35 \mathrm{ml}$ of each sap were placed in a sample holder; then, the reading was measured. Viscosity values are reported using miliPascal seconds (mPa.s).

\section{Total Soluble Solid Measurement}

A hand-held refractometer (ATAGO HSR-500, Japan) was used to measure total soluble solid of the sap. A sap drop was poured into the sample area of the refractometer. Then, the reading was documented. The total soluble solid values are reported in ${ }^{\circ}$ Brix.

\section{pH Determination}

A pH meter (Lab 850 SCHOTT Instruments, Germany) was used to measure the saps' $\mathrm{pH}$. The results are reported as $\mathrm{pH}$ values. Prior to the analysis, standard buffer solutions of $\mathrm{pH} 4$ and $\mathrm{pH}$ 7 were used to calibrate the $\mathrm{pH}$ meter.

\section{Antioxidant Analysis}

Total phenolic content determination. The FolinCiocalteu method (Al-Farsi et al., 2005), were modified to enable us to use the samples directly without extraction, to analyse the total phenolic contents of each sap. The $1 \mathrm{~g}$ of sap was diluted into $10 \mathrm{ml}$ of distilled water in order to prepare the sample. Then, $1.5 \mathrm{ml}$ of Folin-Ciocalteu reagent at $10 \%$ concentration was mixed with $200 \mu$ lof the sample. The solution was set aside for $5 \mathrm{~min}$; it was then mixed with $1.5 \mathrm{ml}$ of $0.56 \mathrm{M}$ sodium carbonate. The mixture was then stored at room temperature in complete darkness for $90 \mathrm{~min}$ before followup observation. A UV visible spectrophotometer, 
Shimadzu UV-160A (Kyoto, Japan) at $725 \mathrm{~nm}$ was used to record the absorbance. The outcome was reported in milligrams of gallic acid equivalent per $100 \mathrm{~g}$ of syrup (GAE mg $100 \mathrm{~g}^{-1}$ ). The gallic acid standard curve was provided for concentrations of 50, 100, 150, 200, 250 and $300 \mathrm{mg}$ litre $^{-1}$.

Determination of free radical scavenging activity and inhibition. The 2, 2- diphenyl-1-picrylhydrazyl (DPPH) method employed by Li and Seeram (2010) and Brand-Williams et al. (1995) was adopted in this study to measure the free radical scavenging activity, and the absorbance reading was measured by recording Trolox (vitamin E) and the standard curves of ascorbic acid (vitamin C).

Statistical analysis. The data were collected in triplicate $(n=3)$. Mean values were presented with \pm standard deviation. SPSS 17.0 software was used to conduct one-way analysis of variance (ANOVA) and Duncan's Multiple-Range Test ( $\mathrm{p}<0.05)$.

\section{RESULTS AND DISCUSSION}

\section{Sugar Content Determination}

Three types of sugar were analysed for each sap: fructose, glucose and sucrose. As shown in Table 1, the saps' sugar contents were significantly different from each other $(\mathrm{p}<0.05)$. The OPT saps had glucose as their main sugar, whereas Nsap had sucrose and fructose as its main sugars.

Generally, as trunk storage time increased, there was an increase in the sugar content of the OPT saps. The sucrose, glucose and fructose contents in OPT0sap were found to be $26.03 \pm 1.29 \mathrm{mg} \mathrm{g}^{-1}, 153.24$ $\pm 11.64 \mathrm{mg} \mathrm{g}^{-1}$ and $18.24 \pm 8.14 \mathrm{mg} \mathrm{g}^{-1}$, respectively. These contents were found to be significantly lower than those of OPT60sap $(\mathrm{p}<0.05)$. Yamada et al. (2010) argue that as storage time increases to 60 days, there will be an increase in the sugar content of OPT saps. At storage stage, some natural enzymes such as invertase and amylase in the trunk hydrolyse the trunk starch (Yamada et al., 2010). It is thought that the starch content of felled trunks decreases because most of the sugar content is used for the survival of living cells in the trunk (Hamid, 2015).

There was significantly more sucrose $(\mathrm{p}<0.05)$ than any other sugars in Nsap $\left(65.48 \pm 0.91 \mathrm{mg} \mathrm{g}^{-1}\right)$, followed by fructose $\left(71.33 \pm 0.60 \mathrm{mg} \mathrm{g}^{-1}\right)$. However, Nsap had a lower glucose content than the two OPT saps, at $31.34 \pm 0.33 \mathrm{mg} \mathrm{g}^{-1}$, whereas the glucose content in OPT saps ranged from $153.24 \pm 11.64 \mathrm{mg}$ $\mathrm{g}^{-1}$ to $200.66 \pm 20.82 \mathrm{mg} \mathrm{g}^{-1}$. The reason for this is that nipa palm's inflorescence portion is responsible for storing sucrose. Studies on coconut palm indicated that this part of the plant contained nearly half of all the sugars, usually in the form of sucrose. The trace contents of fructose and glucose in the inflorescence are commonly regarded as stem (Gomes and Prado, 2007). The same results have been found for nipa trees, as they both come from the Arecaceae family. In spite of the effect of the trunk storage on sap sugar content, the origin of the sap impacted the content. The main sugar content was identical (glucose) in OPT60sap and OPT0sap, since they were obtained from the trunk. However, Nsap demonstrated a different sugar trend, since the sugar was derived from the inflorescence.

TABLE 1. SUGAR CONTENT OF THE SAPS

\begin{tabular}{llll}
\hline \multirow{2}{*}{ Types of sap } & \multicolumn{3}{c}{ Sugar content, mg g $^{-1}$} \\
\cline { 2 - 4 } & Sucrose & Glucose & Fructose \\
\hline OPT0sap & $26.03 \pm 1.29^{\mathrm{a}}$ & $153.24 \pm 11.64^{\mathrm{b}}$ & $18.24 \pm 8.14^{\mathrm{a}}$ \\
OPT60sap & $33.88 \pm 2.86^{\mathrm{b}}$ & $200.66 \pm 20.82^{\mathrm{c}}$ & $60.30 \pm 10.44^{\mathrm{b}}$ \\
& & & \\
Nsap & $65.48 \pm 0.91^{\mathrm{c}}$ & $31.34 \pm 0.33^{\mathrm{a}}$ & $71.33 \pm 0.60^{\mathrm{c}}$ \\
\hline $\begin{array}{l}\text { Note: Values with different superscript letters within the same } \\
\text { column show significant differences (p<0.05). } \\
\text { OPT0sap - first sap; OPT060sap - second sap; Nsap - control } \\
\text { sample. }\end{array}$
\end{tabular}

\section{Colour Determination}

Colour is a function of storage age and can be used to show the sap's quality. The colour analysis of OPT60sap and OPT0sap demonstrated that they were similar in colour, whereas Nsap displayed a lighter colour (Figure 1).
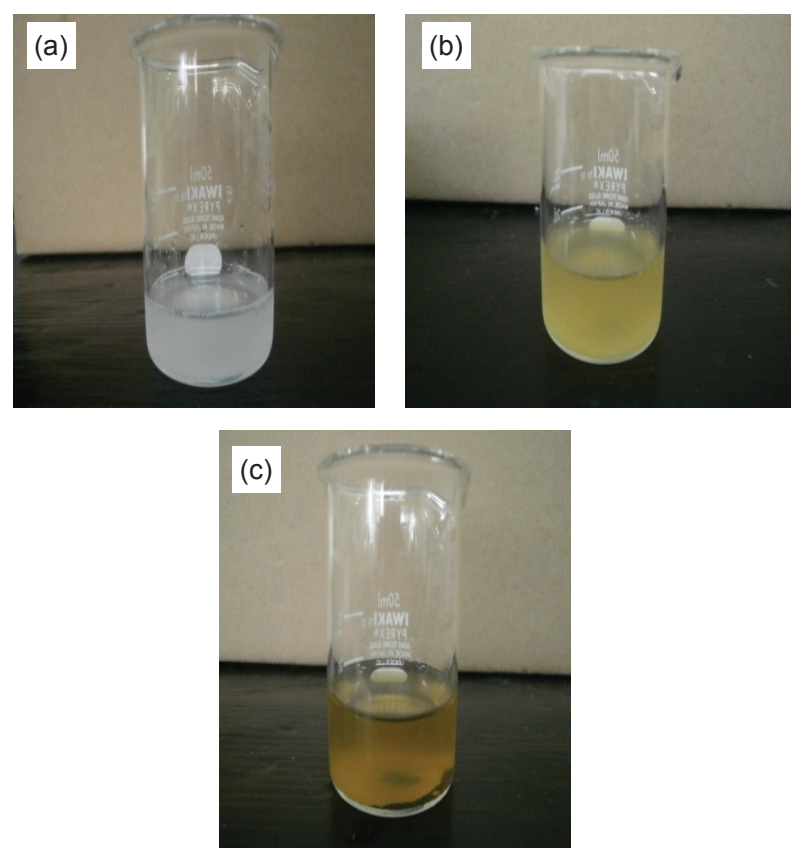

Figure 1. (a) Nsap (control), (b) OPT0sap and (c) OPT60sap. 
The results of the colour analysis are reported as $L^{*}$, $a^{*}$ and $b^{*}$, wherein $L^{*}$ indicates the sap's lightness, which ranges from black (0) to white (100). The $\mathrm{a}^{*}$ symbol represents colours from red to green, with values that range from red (+) to green (-). The $b^{*}$ symbol indicates colours from yellow to blue, with values that range from yellow (+) to blue (-).

As shown in Table 2, storage time significantly affected the sap colours. The findings also suggested that colours were significantly $(\mathrm{p}<0.05)$ different from each other in all the three saps. The sap lightness $\left(L^{*}\right)$ decreased from $72.80 \pm 0.17$ to $68.39 \pm$ 1.38 for OPT0Sap and OPT60sap, respectively.

The results showed that Nsap $L^{*}$ had the maximum lightness value (78.88 \pm 1.56$)$, indicating that OPT60sap was darker than the other two samples. Nsap had the highest lightness value and it had the lowest amounts of $\mathrm{a}^{*}$ and $\mathrm{b}^{*}(1.84 \pm 0.11$ and $8.49 \pm 0.10$ ), indicating that the white colour did not vary much. On the other hand, significantly higher amounts of $\mathrm{a}^{*}$ (red) $(5.88 \pm 0.26)$ and $\mathrm{b}^{*}$ (yellow) were observed in OPT60sap (43.55 \pm 0.11$)$. Both of the OPT saps were found to be yellowish, with $b^{*}$

TABLE 2. COLOUR PROPERTIES OF THE SAPS

\begin{tabular}{lccc}
\hline \multirow{2}{*}{ Types of sap } & \multicolumn{3}{c}{ Colour } \\
\cline { 2 - 4 } & $\mathbf{L}^{*}$ & $\mathbf{a}^{*}$ & $\mathbf{b}^{*}$ \\
\hline OPT0sap & $72.88 \pm 0.17^{\mathrm{b}}$ & $4.29 \pm 0.02^{\mathrm{b}}$ & $42.22 \pm 0.04^{\mathrm{b}}$ \\
OPT60sap & $68.39 \pm 1.38^{\mathrm{a}}$ & $5.88 \pm 0.26^{\mathrm{c}}$ & $43.55 \pm 0.11^{\mathrm{c}}$ \\
Nsap & $78.88 \pm 1.56^{\mathrm{c}}$ & $1.84 \pm 0.11^{\mathrm{a}}$ & $8.49 \pm 0.10^{\mathrm{a}}$ \\
\hline
\end{tabular}

Note: Values with different superscript letters within the same column refer to significant difference $(\mathrm{p}<0.05)$.

OPT0sap - first sap; OPT060sap - second sap; Nsap - control sample.

$\mathrm{L}^{*}$ - sap's lightnness ranges from black (0) to white (100).

$\mathrm{a}^{*}$ - colours from red (+) to green (-).

$\mathrm{b}^{*}$ - colours from yellow $(+)$ to blue $(-)$.

values of $43.55 \pm 0.11$ (OPT60sap) and $42.22 \pm 0.04$ (OPT0sap). However, OPT60sap had a significantly darker colour $(\mathrm{p}<0.05)$. This dark colour is due to chemical activity, such as the enzymatic browning of phenolic compounds by polyphenol oxidase (Banerji et al., 2012), which usually takes place over the 60 days of trunk storage. Hence, it could be safely concluded that trunk time storage significantly affects the colour of OPT saps.

\section{Viscosity Measurement}

Viscosity refers to a fluid's resistance to flowing (The American Heritage, 2015). The higher the viscosity, the harder it is for the solution or fluid to flow (i.e. the fluid is thicker), since the fluid compounds are more concentrated (Raventós et al., 2007). Table 3 reveals the viscosity values of
OPT0sap, Nsap and OPT60sap. The saps' viscosities were reported to be significantly different $(p<0.05)$ from each other. The viscosity value was found to be proportional to the value of total soluble solid content of each sap, having the following correlation: $R^{2}=0.893(y=2.957 x+4.494)$.

OPT0sap had the lowest viscosity, at $0.87 \pm 0.07$ mPa.s, while Nsap had the highest value, at $3.77 \pm 0.09$ mPa.s. According to James et al. (2009), sap viscosity could be the result of the interaction of chemical compounds in the sap, which contains phytochemicals, sugars, and organic acids. OPT0sap, with viscosity of $0.87 \pm 0.07 \mathrm{mPa} . \mathrm{s}$, showed the lowest amount of total

TABLE 3. DATA FOR VISCOSITY, TOTAL SOLUBLE SOLID AND $\mathrm{pH}$ OF THE SAPS

\begin{tabular}{lccc}
\hline \multirow{2}{*}{ Type of syrup } & \multicolumn{3}{c}{ Results } \\
\cline { 2 - 4 } & $\begin{array}{c}\text { Viscosity, } \\
\text { mPa.s }\end{array}$ & $\begin{array}{c}\text { Total soluble } \\
\text { solid, } \\
{ }^{\circ} \text { Brix }\end{array}$ & pH \\
\hline OPT0sap & $0.87 \pm 0.07^{\mathrm{a}}$ & 6 & $5.27 \pm 0.01^{\mathrm{a}}$ \\
OPT60sap & $1.96 \pm 0.16^{\mathrm{b}}$ & 12 & $5.31 \pm 0.01^{\mathrm{b}}$ \\
Nsap & $3.77 \pm 0.09^{\mathrm{c}}$ & 15 & $6.20 \pm 0.02^{\mathrm{c}}$ \\
\hline
\end{tabular}

Note: Values with different superscript alphabets within the same column refer to significance difference $(\mathrm{p}<0.05)$. OPT0sap - first sap; OPT060sap - second sap; Nsap - control sample.

soluble solid content of $6{ }^{\circ}$ Brix, whereas Nsap, with viscosity of $3.77 \pm 0.09 \mathrm{mPa}$.s, demonstrated a higher amount of total soluble solid content of $15{ }^{\circ}$ Brix. According to Kim (2010), the relationship between sugar content and viscosity is an exponentially increasing interaction. As the findings suggest, the viscosity of OPT0sap was lower $(\mathrm{p}<0.05)$ than that of OPT60sap $(0.87 \pm 0.07 \mathrm{mPa}$.s to $1.96 \pm 0.16 \mathrm{mPa} . \mathrm{s})$. This indicates that trunk storage time significantly affects the sap's viscosity.

\section{Measurement of Total Soluble Solid Content}

A sap's total soluble solid content is generally computed based on its sugar content (Stuckel and Low, 1996). In other words, total soluble solid content can be shown by a sap's total sugar. As demonstrated in the results presented above, the saps' origin and storage time significantly influence the total soluble solid contents.

There was an increase in OPT saps' total soluble solid content from $6{ }^{\circ}$ Brix to $12{ }^{\circ}$ Brix in OPT0sap and OPT60sap, respectively (Table 3). This result suggests that when the trunk is stored, the sap's chemical composition changes and trunk sugar concentration increases. Yamada et al. (2010) argue 
that during trunk storage, starch changes into sugars. As the cut oil palm trunk is under stressful conditions, such as cold stress (Maruyama et al., 2009), water stress, and osmotic stress (Wang et al., 2000), it starts to release certain natural enzymes, such as amylase, which converts the starch into simpler forms, like sugars (Yamada et al., 2010). The longer the storage time, the more enzymes the trunk releases; these enzymes convert more starch into sugars (Yamada et al., 2010). It is, thus, implied that trunk storage time impactssaps' total soluble solid content.

Total soluble solid content was the highest in Nsap (15 ${ }^{\circ}$ Brix $)$, since Nsap was collected from the inflorescence part of the oil palm. Starch in oil palm is stored in the trunk and is commonly dispersed upwards toward the stem apex (Dalibard, 1999). For nipa palm, the inflorescence is located in the stem apex; therefore, the stem apex has high amounts of sugar, which results in high total soluble solid content.

Both OPT60sap and OPT0sap were collected from the trunk, where the sugars are usually in the form of starch. The phloem and xylem are the origins of sap in the trunk: they are responsible for the transfer of carbohydrates and water from the leaf to other sections of the tree. Thus, compared to Nsap, OPT0sap and OPT60sap had lower amounts of total soluble solid content. It is thus implied that the site from which sap is collected impacts the overall value of the total soluble solid content: in the OPT saps, the total soluble solid content ranged from 6-12 ${ }^{\circ}$ Brix.

\section{pH Determination}

The $\mathrm{pH}$ represents the sap's organic acid content. Organic acid contains acidic features; $\mathrm{H}^{+}$ions are released as organic acid dissociates in water (Theron and Lues, 2010). In addition, $\mathrm{pH}$ value shows the sap's microbial contamination, because some kinds of acids, such as acetic acid, lactic acid, and other organic acids, are released through bacterial action (Lagacé et al., 2015).

The saps' $\mathrm{pH}$ values were found to be significantly different $(\mathrm{p}<0.05)$ from each other with a range from 5.27 to 6.20 . The lowest $\mathrm{pH}$ belonged to the OPT0sap, while the highest belonged to Nsap. As shown in Table 3, the OPT0sap's pH value was significantly less $(\mathrm{p}<0.05)$ than that of OPT60sap $(5.31 \pm 0.01)$. This suggests that the polysaccharides formed from starch hydrolysis during storage of the trunk hinder the movement of the ionic compounds $\left(\mathrm{H}^{+}\right)$in OPT60sap, thus lowering its acidity (increasing its $\mathrm{pH}$ ). It is worth mentioning that different types of organic acids as well as different concentrations led to the differences in the $\mathrm{pH}$ values in the saps (Alanazi, 2010). Similar to the findings reported by Kosugi et al. (2010), the present results showed that the OPT saps' $\mathrm{pH}$ values were closer to neutral $\mathrm{pH}$ ( $\mathrm{pH}$ 7). Furthermore, compared to Nsap, OPT60sap and OPT0sap had closer $\mathrm{pH}$ values, since the OPT saps contain the same kinds of organic acids. Literature has also demonstrated that nipa sap contains small amounts of acetic and lactic acid (Tamunaidu et al., 2013), whereas OPT saps possess malic and citric acid (Kosugi et al., 2010).

\section{Antioxidant Analysis}

Total phenolic content determination. Phenolic compounds commonly possess a hydroxyl group and an aromatic ring. These compounds are categorised based on their chemical structures, such as their arrangement or the number of phenolic rings. Some examples of such groups are flavonoids, phenolic acids, tannins, quinones, and lignans (Huang et al., 2009). Phenolic compounds are known for their anti-bacterial, antioxidant, and anti-mutagenic activities (Huang et al., 2009). Phenolic compounds in plants are related to metabolic activities and contribute to flavour and colour (Kermasha et al., 1995). The present study attempted to examine the influence of the origin of sap and storage on the phenolic compounds.

An equivalent of gallic acid was used to present the total phenolic content in the saps. The OPT0sap's total phenolic content was $74.91 \pm 1.60 \mathrm{mg}$ GAE 100 $\mathrm{g}^{-1}$. This result was significantly less $(\mathrm{p}<0.05)$ than that of OPT60sap $\left(112.07 \pm 1.33 \mathrm{mg}\right.$ GAE $\left.100 \mathrm{~g}^{-1}\right)$. As Table 4 shows, OPT saps' total phenolic contents were significantly greater $(\mathrm{p}<0.05)$ than that of Nsap. This is due to the phytochemical compounds collected in the xylem of the plant ( $\mathrm{Li}$ and Seeram, 2010) from which the OPT saps were collected, whereas Nsap was collected from the inflorescence parts. Generally, the results demonstrated that the variations in the saps' total phenolic content are due to the source and trunk storage time. Therefore, the same factors could account for the total phenolic content in the syrup products.

Determination of free radical scavenging activity and inhibition. The DPPH method was employed to determine the free radical scavenging activity. This study relied on two kinds of standards for assessing free radical scavenging activity. The saps' scavenging activities were found to be: $i)$ vitamin $\mathrm{C}$ equivalent antioxidant capacity (VCEAC), where ascorbic acid is regarded as the standard; and ii) Trolox equivalent antioxidant capacity (TEAC), which indicates vitamin E. Table 4 displays the free radical scavenging activities and percentage inhibition.

As these results show, the OPT0sap's free radical scavenging activities had a significantly lower value $(p<0.05)$ than that of OPT60sap. This indicates that 
TABLE 4. FREE RADICAL SCAVENGING ACTIVITY, TOTAL PHENOLIC CONTENT AND PERCENTAGE INHIBITION OF SAPS

\begin{tabular}{|c|c|c|c|c|}
\hline \multirow[b]{2}{*}{ Type of syrup } & \multicolumn{4}{|c|}{ Results, mg $100 \mathrm{~g}^{-1}$} \\
\hline & VCEAC & TEAC & $\%$ Inhibition & $\begin{array}{l}\text { Total phenolic content } \\
\left(\mathrm{mg} \mathrm{GAE} 100 \mathrm{~g}^{-1}\right)\end{array}$ \\
\hline OPT0sap & $26.36 \pm 0.07^{\mathrm{b}}$ & $40.81 \pm 0.11^{\mathrm{b}}$ & 80.87 & $74.91 \pm 1.60^{\mathrm{b}}$ \\
\hline OPT60sap & $28.13 \pm 0.33^{c}$ & $43.55 \pm 0.51^{c}$ & 86.46 & $112.07 \pm 1.33^{c}$ \\
\hline Nsap & $11.69 \pm 0.91^{\mathrm{a}}$ & $18.10 \pm 1.42^{\mathrm{a}}$ & 35.48 & $20.06 \pm 3.22^{\mathrm{a}}$ \\
\hline
\end{tabular}

Note: Values with different superscript letters within the same column show significant differences $(p<0.05)$. OPT0sap - first sap; OPT060sap - second sap; Nsap - control sample. VCEAC - Vitamin C equivalent antioxidant capacity. TEAC - Trolox equivalent antioxidant capacity.

as storage time increases, the value of antioxidant compounds rises, which in turn contributes to greater free radical scavenging activity. This trend was found to be the same for both vitamin $\mathrm{E}$ and vitamin C. Nevertheless, TEAC values were greater than VCEAC values, ranging from $40.81 \pm 0.11 \mathrm{mg}$

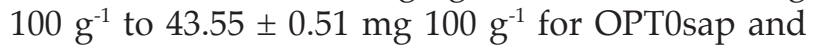
OPT60sap, respectively. It could be concluded that in the OPT, there were more vitamin E compounds (e.g. tocopherols) than vitamin C. Nsap had the lowest $(\mathrm{p}<0.05)$ amounts of vitamin E $(18.10 \pm 1.42$ $\left.\mathrm{mg} 100 \mathrm{~g}^{-1}\right)$ and vitamin C (11.69 $\left.\pm 0.91 \mathrm{mg} 100 \mathrm{~g}^{-1}\right)$. The low activities in Nsap showed that it had lower antioxidant compounds, with the same trend as total phenolic content. The maximum amounts of free radical scavenging activities in OPT60sap and OPT0sap demonstrate that the saps collected from oil palm trunk could have greater nutritional value.

The free radical scavenging activities were also represented by the percentage inhibition. The standard curve showed a $50 \%$ value of inhibition $\left(\mathrm{IC}_{50}\right)$. Vitamins $\mathrm{E}$ and $\mathrm{C}$ had $\mathrm{IC}_{50}$ of $14.28 \mathrm{mg}$ TEAC $100 \mathrm{~g}^{-1}$ and $9.41 \mathrm{mg}$ VCEAC $100 \mathrm{~g}^{-1}$ respectively, implying that these amounts of antioxidant would be required in order to prevent over $50 \%$ of free radical activities.

Further, the OPT60sap and OPT0sap had inhibition of more than $50 \%$, with values of $86.46 \%$ and $80.87 \%$ respectively, thus indicating that OPT saps clearly had greater free radical scavenging activities than Nsap (35.48\%). It was also found that the storage of trunk enhances the sap's antioxidant compounds, as OPT60sap had a greater value than OPT0sap.

\section{CONCLUSION}

The results indicated that chemical and physical features of Nsap, OPT0sap and OPT60sap were significantly different from each other $(p<0.05)$. The analysis of the two OPT saps revealed that trunk storage significantly impacted the saps' compositions. The storage time impacted the OPT sap's colour, as the sap became darker after storage. It was also witnessed that other compounds in the sap changed with trunk storage. With longer storage, the sugar content increases especially glucose and fructose, such increase in sugar contents improves the potential of OPT saps to be changed into syrup. Further, the OPT saps demonstrated greater antioxidant contents than did Nsap. In comparison to Nsap, the OPT saps had better qualities related to sugar content and antioxidant capacity. Generally, oil palm trunk saps have potential to be made into syrup to be used as food ingredient based on the sugar content and antioxidant capacity.

\section{REFERENCES}

Al-Farsi, M; Alasalvar, C; Morris, A; Baron, M and Shahidi, F (2005). Comparison of antioxidant activity, anthocyanins, carotenoids, and phenolics of three native fresh and sun-dried date (Phoenix dactylifera L.) varieties grown in Oman. J. Agr. Food Chem., 53(19): 7592-7599.

Alanazi, F K (2010). Utilisation of date syrup as a tablet binder, comparative study. Saudi Pharm J., 18(2): 81-89.

Banerii, R; Singh, P; Anwar, S I and Solomon, S (2012). Effect of reducing sugars on non-enzymic browning during thermo-evaporation of sugarcane juice for making jaggery. Sugar Tech., 14(4): 428-431.

Bazinet, L; Gaudreau, H; Lavigne, D and Martin, N (2007). Partial demineralisation of maple sap by electrodialysis: Impact on syrup sensory and physicochemical characteristics. J. Sci. Food and Agri., 87(9): 1691-1698.

Brand-Wiliams, W; Cuvelier, M E and Berset, C L W T (1995). Use of a free radical method to evaluate antioxidant activity. LWT-Food Science and Technology, 28(1): 25-30. 
Dalibard, C (1999). Overall view on the tradition of tapping palm trees and prospects for animal production. Livestock Research for Rural Development, 11(1): 1-37.

Goh, C S; Tan, H T; Lee, K T and Brosse, N (2011). Evaluation and optimisation of organosolv pretreatment using combined severity factors and response surface methodology. Biomass and Bioenergy, 35(9): 4025-4033.

Gomes, F P and Prado, C H (2007). Ecophysiology of coconut palm under water stress. Braz J. Plant Physiology, 19(4): 377-391.

Hamid, Z A A; Takamitsu, A; Mhd, R S F; Akihiko, K; Othman, S; Rokiah, H and Satoru, N (2015). Analysis of free sugar and starch in oil palm trunks (Elaeis guineensis Jacq.) from various cultivars as a feedstock for bioethanol production. Int. J. Green Energy. https: / / doi.org/10.1080/15435075.2014.910 786.

Huang, W Y; Cai, Y Z and Zhang, Y (2009). Natural phenolic compounds from medicinal herbs and dietary plants: Potential use for cancer prevention. Nutrition and Cancer, 62(1): 1-20.

James, O O; Mesubi, M A; Usman, L A; Yeye, S $\mathrm{O}$; Anjaku, K O; Ogunniran, $\mathrm{K} \mathrm{O}$; Ajani, $\mathrm{O} \mathrm{O}$ and Siyanbola, T O (2009). Physical characterisation of some honey samples from North-Central Nigeria. Int. J. Phys. Sci., 4(9): 464-470.

Kermasha, S; Goetghebeur, M and Dumont, J (1995). Determination of phenolic compound profiles in maple products by high-performance liquid chromatography. J. Agr. and Food Chem., 43(3): 708716.

Kim, E (2010). Relationship between viscosity and sugar concentration in aqueous sugar solution using the Stokes' Law and Newton's First Law of Motion. The University of British Columbia, Vancouver, Canada. 6 pp.

Kosugi, A; Tanaka, R; Magara, K; Murata, Y; Arai, T; Othman, S; Rokiah, H; Zubaidah Aimi, A H; Mohd Khairul, A Y; Mohd Nor, M Y; Wan Asma, I and Mori, Y (2010). Ethanol and lactic acid production using sap squeezed from old oil palm trunks felled for replanting. J. Biosci. and Bioeng., 110(3): 322-325.

Lagacé, L; Leclerc, S; Charron, C and Sadiki, M (2015). Biochemical composition of maple sap and relationships among constituents. J. Food Compos and Analysis, 41: 129-136.
Li, L and Seeram, N P (2010). Maple syrup phytochemicals include lignans, coumarins, a stilbene, and other previously unreported antioxidant phenolic compounds. J. Agri and Food Chem., 58(22): 11673-11679.

Lokesh, B E; Hamid, Z A A; Arai, T; Kosugi, A; Murata, Y; Hashim, R; Othman, S; Mori, Y and Sudesh, K (2012). Potential of oil palm trunk sap as a novel inexpensive renewable carbon feedstock for polyhydroxyalkanoate biosynthesis and as a bacterial growth medium. Clean-Soil, Air, Water, 40(3): 310-317.

Maruyama, K; Takeda, M; Kidokoro, S; Yamada, K; Sakuma, Y; Urano, K; Fujita, M; Yoshiwara, K; Matsukura, S; Morishita, Y; Sasaki, R; Suzuki, H; Saito, K; Shibata, D; Shinozaki, K and YamaguchiShinozaki, K (2009). Metabolic pathways involved in cold acclimation identified by integrated analysis of metabolites and transcripts regulated by DREB1A and DREB2A. Plant Physiology, 150(4): 1972-1980.

Mumtaz, T; Yahaya, NA;Abd-Aziz, S; Yee, P L; Shirai, $Y$ and Hassan, M A (2010). Turning waste to wealthbiodegradable plastics polyhydroxyalkanoates from palm oil mill effluent - A Malaysian perspective. J. Clean Prodn., 18(14): 1393-1402.

Murata, Y; Tanaka, R; Fujimoto, K; Kosugi, A; Arai, $\mathrm{T}$ Togawa, E; Takano, T; Ibrahim, W A; Elham, P; Sulaiman, O; Hashim, R and Mori, Y (2013). Development of sap compressing systems from oil palm trunk. Biomass and Bioenergy, 51: 8-16.

Noparat, P and Prasertsan, P (2011). Isolation and characterization of high hydrogen producing strain Clostridium beijerinckii PS-3 from fermented oil palm sap. Int. J. Hydrogen Energy, 36(21): 14086-14092.

Phaichamnan, M; Posri, W and Meenune, M (2010). Quality profile of palm sugar concentrate produced in Songkhla province, Thailand. Int. Food Res. J., 17: 425-432.

Raventós, M; Hernández, E; Auleda, J and Ibarz, A (2007). Concentration of aqueous sugar solutions in a multi-plate cryoconcentrator. J. Food Eng., 79(2): 577-585.

Shahirah, M N N; Gimbun, J; Pang, S F; Zakria, R M; Cheng, C K; Chua, G K and Asras, M F F (2015). Influence of nutrient addition on the bioethanol yield from oil palm trunk sap fermented by Saccharomyces cerevisiae. J. Indust. and Eng. Chem., 23: 213-217. 
Stuckel, J G and Low, N H (1996). The chemical composition of 80 pure maple syrup samples produced in North America. Food Research International, 29: 373-379.

Tamunaidu, P; Matsui, N; Okimori, Y and Saka, S (2013). Nipa (Nypa fruticans) sap as a potential feedstock for ethanol production. Biomass and Bioenergy, 52: 96-102.

The American Heritage (2015). New Dictionary of Cultural Literacy. http:/ / dictionary.reference.com/ browse/ viscosity, accessed on 17 September 2015.

Theron, M M and Lues, J R (2010). Organic Acids and Food Preservation. First edition. CRC Press. 167 pp.
Wang, H L; Lee, P D; Chen, W L; Huang, D J and $\mathrm{Su}, \mathrm{J}$ C (2000). Osmotic stress-induced changes of sucrose metabolism in cultured sweet potato cells. J. Experimental Botany, 51(353): 1991-1999.

Yamada, H; Tanaka, R; Sulaiman, O; Hashim, R; Hamid, Z A A; Yahya, M K A and Yamamoto, K (2010). Old oil palm trunk: A promising source of sugars for bioethanol production. Biomass and Bioenergy, 34(11): 1608-1613.

Yunus, R; Fakhrul I-Razi, A; Ooi, T L; Iyuke, S E and Idris, A (2003). Preparation and characterisation of trimethylolpropane esters from palm kernel oil methyl esters. J. Oil Palm Res. Vol. 15(2): 42-49.

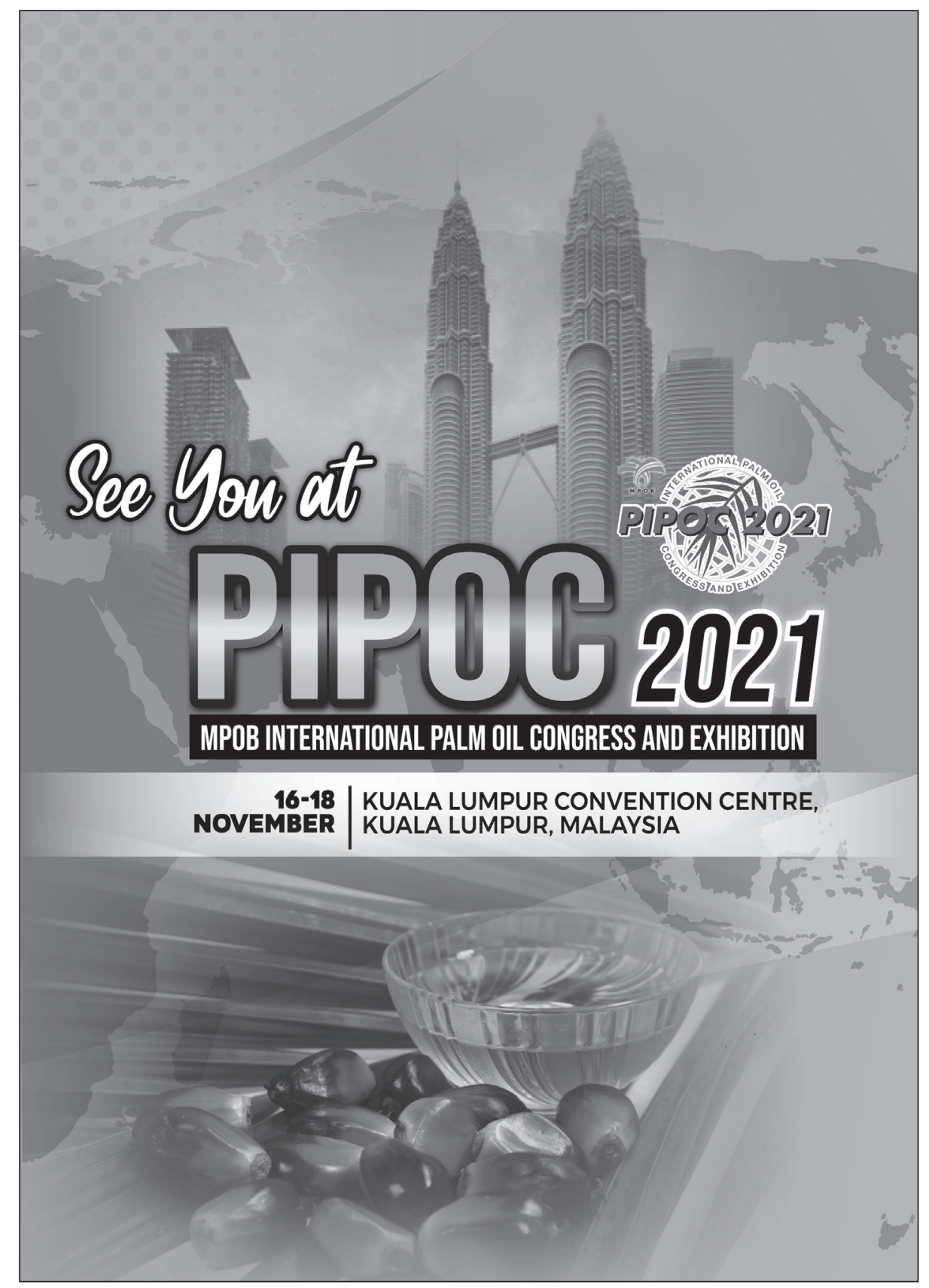

